\title{
EFFECTIVE RANGES OF A MODELED OPEN LIMESTONE CHANNEL
}

\author{
DAVID WOLFE* \\ FACULTY ADVISOR: YING LI** \\ Department of Mathematics and Engineering \\ Saint Francis University \\ Loretto, PA 15940
}

\begin{abstract}
Acid mine drainage (AMD) is the outflow of acidic water from metal mines or coal mines. When exposed to air and water, metal sulfides from the deposits of the mines are oxidized and produce acid, metal ions and sulfate, which lower the $\mathrm{pH}$ value of the water. An open limestone channel (OLC) is a passive and low cost way to neutralize AMD. A mathematical model has been created to numerically determine the change in $\mathrm{pH}$ of the water and the concentrations of species from the dissolution of calcium on the surface of the limestone into the acidic water. The model is used to predict the conditions in which a OLC would be an effective solution for AMD. Effective ranges are determined for the concentrations of calcium and iron, as well as the temperature and velocity of the water.
\end{abstract}

\section{INTRODUCTION}

Acid mine drainage (AMD) is the outflow of acidic water from metal mines or coal mines. When exposed to air and water, metal sulfides, the E-mail addresses: dkw100@francis.edu*; YLi@francis.edu**. 
EFFECTIVE RANGES OF A MODELED OPEN LIMESTONE CHANNEL

majority of which is iron, from the deposits in the mines are oxidized, and produce acidic water, metal ions and sulfate. This process will result in a lower overall $\mathrm{pH}$ value of the water. The water is then unfit for consumption, agricultural or industrial use. AMD has become one of the largest problems in the mining industry.

There have been various methods used to treat AMD. Some of them are expensive and hard to maintain. An open limestone channel (OLC) is a passive and low cost way to treat AMD. Coarse limestone boulders are placed into water downstream of the mine opening. The dissolution of calcium into the water will increase the $\mathrm{pH}$ value of the water. This is achieved from the reaction of calcium carbonate on the surface of the limestone with the acid components of the water. Meanwhile with time passing, the oxidation of metal causes the accumulation of iron and aluminum precipitates at the surface of limestone which hinders the dissolution of calcium. Studies in the 1970s [1], [2], [3] showed that limestone armored with metal oxides releases calcium at a $20 \%$ rate of the unarmored one. Experiments conducted by Zimekiewicz et al. [4] investigated the factors that affect the performance of the open limestone treatment.

We study the problem from a mathematical point of view. A mathematical model has previously been created [5] to process data taken from numerous experiments. The model will now be utilized to establish a practical application to the processed data. The purpose of this paper will be to establish reasonable boundaries for which an OLC would be a solution for AMD remediation. Section 2 explains the mechanism of an open limestone channel. The underlying differential equation is presented in Section 3. Numerical results are given in Section 4. In addition, full tables of values produced from the model will be presentedin the supplemental material. 


\section{Chemical Reaction}

The dissolution of calcium carbonate from limestone is the main chemical reaction occurring in an open limestone channel. It can be described by the following chemical formulas [6]

$$
\begin{aligned}
& \mathrm{CaCO}_{3(\mathrm{~s})}+2 \mathrm{H}^{+} \longleftrightarrow \mathrm{Ca}^{2+}+\mathrm{H}_{2} \mathrm{CO}_{3}{ }^{*}, \\
& \mathrm{CaCO}_{3(\mathrm{~s})}+\mathrm{H}_{2} \mathrm{CO}_{3}{ }^{*} \longleftrightarrow \mathrm{Ca}^{2+}+2 \mathrm{HCO}_{3}^{-}, \\
& \mathrm{CaCO}_{3(\mathrm{~s})}+\mathrm{H}_{2} \mathrm{O} \longleftrightarrow \mathrm{Ca}^{2+}+\mathrm{HCO}_{3}^{-}+\mathrm{OH}^{-},
\end{aligned}
$$

where $\left[\mathrm{H}_{2} \mathrm{CO}_{3}^{*}\right]=\left[\mathrm{CO}_{2(\mathrm{aq})}\right]+\left[\mathrm{H}_{2} \mathrm{CO}_{3}^{0}\right]$. Square brackets [ ] define concentrations in solution, and curly brackets \{\} will be used to denote activities, both in $\mathrm{mol} / \mathrm{L}$.

The metal precipitate at the surface of limestone is considered to be $\mathrm{Fe}(\mathrm{OH})_{3}$ produced by iron ions. The reaction is as follows

$$
\mathrm{Fe}^{3+}+3 \mathrm{HCO}_{3}{ }^{-} \longrightarrow \mathrm{Fe}(\mathrm{OH})_{3(\mathrm{~s})}+3 \mathrm{CO}_{2}
$$

Assuming the system is at chemical equilibrium, we can calculate the concentrations of all species in solution by applying mass balance and charge balance equations in the system. In the following, we will set up a chemical equilibrium model for the system. Readers are referred to [7] for a more detailed explanation of the numerical method used to solve chemical equilibrium problems. 
EFFECTIVE RANGES OF A MODELED OPEN LIMESTONE CHANNEL

To compute the concentrations of species, we consider the following reactions

$$
\begin{aligned}
& \mathrm{H}_{2} \mathrm{CO}_{3}{ }^{*} \rightleftharpoons \mathrm{H}^{+}+\mathrm{HCO}_{3}^{-}, \\
& \mathrm{HCO}_{3}{ }^{-} \rightleftharpoons \mathrm{H}^{+}+\mathrm{CO}_{3}^{2-}, \\
& \mathrm{H}_{2} \mathrm{O} \rightleftharpoons \mathrm{H}^{+}+\mathrm{OH}^{-},
\end{aligned}
$$

with the following equilibrium constants, respectively

$$
\begin{aligned}
& K_{1}=\frac{\left\{\mathrm{H}^{+}\right\}\left\{\mathrm{HCO}_{3}^{-}\right\}}{\left\{\mathrm{H}_{2} \mathrm{CO}_{3}{ }^{*}\right\}}, \\
& K_{2}=\frac{\left\{\mathrm{H}^{+}\right\}\left\{\mathrm{CO}_{3}^{2-}\right\}}{\left\{\mathrm{HCO}_{3}{ }^{-}\right\}}, \\
& K_{\mathrm{w}}=\left\{\mathrm{H}^{+}\right\}\left\{\mathrm{OH}^{-}\right\} .
\end{aligned}
$$

The species in the solution are assumed to be: $\left[\mathrm{H}^{+}\right],[\mathrm{OH}-],\left[\mathrm{H}_{2} \mathrm{CO}_{3}{ }^{*}\right]$, $\left[\mathrm{HCO}_{3}-\right],\left[\mathrm{CO}_{3}{ }^{2}-\right],\left[\mathrm{Ca}^{2+}\right]$. The controlling factor of the mechanisms occuring in the channel is considered to be $\left[\mathrm{Ca}^{2+}\right]$. The concentration of a metal species, $\left[\mathrm{Fe}^{3+}\right]$, is found directly from the concentration of $\left[\mathrm{H}^{+}\right]$as shown in equation (3.10), which is presented later in the next section. They satisfy the mass balance equation with respect to the concentration of $\mathrm{Ca}^{2+}$ and the charge balance equation

$$
\left[2 \mathrm{H}^{+}\right]+\left[\mathrm{Ca}^{2+}\right]=\left[\mathrm{OH}^{-}\right]+\left[\mathrm{HCO}_{3}^{-}\right]+\left[\mathrm{CO}_{3}^{2-}\right] .
$$

The chemical equilibrium equations for each species are written in logarithimic form. From the following series of equations, the rate constants 
that require a numeric value are determined.

$$
\begin{aligned}
& \log \left[\mathrm{H}^{+}\right]=\log \left[\mathrm{H}^{+}\right]+\log \kappa_{1}, \\
& \log \left[\mathrm{OH}^{-}\right]=-\log \left[\mathrm{H}^{+}\right]+\log \kappa_{2}, \\
& \log \left[\mathrm{H}_{2} \mathrm{CO}_{3}\right]=\log \left[\mathrm{H}_{2} \mathrm{CO}_{3}{ }^{*}\right]+\log \kappa_{3}, \\
& \log \left[\mathrm{HCO}_{3}{ }^{-}\right]=\log \left[\mathrm{H}_{2} \mathrm{CO}_{3}{ }^{*}\right]+\log \left[\mathrm{H}^{+}\right]+\log \kappa_{4}, \\
& \log \left[\mathrm{CO}_{3}{ }^{2-}\right]=\log \left[\mathrm{H}_{2} \mathrm{CO}_{3}{ }^{*}\right]-2 \log \left[\mathrm{H}^{+}\right]+\log \kappa_{5}, \\
& \log \left[\mathrm{Ca}^{2+}\right]=\log \left[\mathrm{Ca}^{2+}\right]+\log \kappa_{6},
\end{aligned}
$$

where $\kappa_{i}, i=1, \ldots, 6$ are the equilibrium constants for the corresponding reactions. It is obvious that $\log \kappa_{1}=\log \kappa_{3}=\log \kappa_{6}=0$, indicating that no numeric value will be assigned. It can also be noted that $\kappa_{2}$ is equivalent to $K_{\mathrm{w}}$, as defined in (2.10). This constant and the others are defined by experiments as functions depending on temperature of the stream.[8] In the following equations the temperature, designated $T$ in units of Kelvin, gives the equilibrium constant at a specified temperature.

$$
\begin{aligned}
& \log \kappa_{2}=\log K_{\mathrm{w}}=6.0875-\frac{4470.99}{T}-0.01706 T \\
& \log \kappa_{4}=14.8435-\frac{3404.71}{T}-0.03279 T \\
& \log \kappa_{5}=21.3415-\frac{6307.1}{T}-0.05658 T
\end{aligned}
$$

These equation are used in combination with the mass balance and charge balance equation (2.11) to obtain a system of 6 nonlinear equations with the 6 species as variables. We then solve the nonlinear system of equations by Newton-Raphson method. The initial value of calcium obtained experimentally will be input into this system, as well as an initial guess for the concentration of hydrogen in the system. For all calculations done in this paper, the initial guess for the amount of hydrogen is set at $10^{-9} \mathrm{M}$. For 
the channel studied at the Swank 13 site, the initial calcium concentration at the top of the channel was determined to be $3.68 * 10^{-5} \mathrm{M}$ by chemistry students using flame atomic absorption spectroscopy under the supervision of Dr. Edward Zovinka. This value is considered to be the concentration of the calcium in the bulk water, and what is produced from the speciation using Newton-Raphson is considered to be the concnetration at the surface of the limestone.

\section{RATE EQUATiON}

The rate of dissolution of calcite $r\left(\mathrm{mmol} / \mathrm{cm}^{2} / \mathrm{s}\right)$, determined by the chemical reactions $(2.1),(2.2),(2.3)$, is given by the following equation [9]

$$
r=k_{1} a_{\mathrm{H}^{+}}+k_{2} a_{\mathrm{H}_{2} \mathrm{CO}_{3}}{ }^{*}+k_{3} a_{\mathrm{H}_{2} \mathrm{O}}-k_{4} a_{\mathrm{Ca}^{2+}} a_{\mathrm{HCO}_{3}}{ }^{-},
$$

where $a_{\mathrm{H}^{+}}, a_{\mathrm{H}_{2} \mathrm{CO}_{3}}{ }^{*}, a_{\mathrm{H}_{2} \mathrm{O}}, a_{\mathrm{Ca}^{2+}}, a_{\mathrm{HCO}_{3}}$ are the activities of $\mathrm{H}^{+}, \mathrm{H}_{2} \mathrm{CO}_{3}{ }^{*}$, $\mathrm{H}_{2} \mathrm{O}, \mathrm{Ca}^{2+}$ and $\mathrm{HCO}_{3}^{-}$, which are assumed in this work to be the same as concentrations. The first order rate constants $k_{1}, k_{2}, k_{3}(\mathrm{~cm} / \mathrm{s})$ are defined as

$$
\begin{aligned}
& \log k_{1}=0.198-\frac{444}{T}, \\
& \log k_{2}=2.84-\frac{2177}{T}, \\
& \log k_{3}= \begin{cases}-5.86-\frac{317}{T} & 5^{\circ} \mathrm{C}<=T<=25^{\circ} \mathrm{C}, \\
-1.10-\frac{1737}{T} & 25^{\circ} \mathrm{C}<T<=48^{\circ} \mathrm{C} .\end{cases}
\end{aligned}
$$

The rate constant of the precipitation reaction $k_{4}(\mathrm{~cm} / \mathrm{s})$ is defined as

$$
k_{4}=\frac{K_{2}}{K c}\left[k_{1}^{\prime}+\frac{1}{a_{\mathrm{H}^{+}}}\left(k_{2} a_{\mathrm{H}_{2} \mathrm{CO}_{3}}{ }^{*}+k_{3} a_{\mathrm{H}_{2} \mathrm{O}}\right)\right],
$$

where $K_{2}$ is the equilibrium constant for dissociation of bicarbonate, $K_{C}$ is the solubility product constant for calcite, $k_{1}^{\prime}$ is a modified forward rate 
EFFECTIVE RANGES OF A MODELED OPEN LIMESTONE CHANNEL

constant for reaction $(2.1)$, which is about $(10 \sim 20) k_{1}$. This equation can be solved directly if operating under the assumption that no iron precipitate has built up on the limestone surface and hence that the concentration of calcium in the bulk solution is equivalent to the concentration at the surface. These are the conditions found at the beginning of the channel before the calcium carbonate reactions have occured and iron has precipitated.

When there is a layer of metal precipitate on the limestone surface, another approach is warranted. An approximation of Ficks first law of diffusion [7] gives the mass flux of $\mathrm{Ca}^{2+}$ from the surface of limestone through the metal sediment layer, in our case, $\mathrm{Fe}(\mathrm{OH})_{3}$, into the bulk solution

$$
J_{\mathrm{d}}=\frac{D}{\delta}\left(\left[\mathrm{Ca}^{2+}{ }_{(\mathrm{s})}\right]-\left[\mathrm{Ca}^{2+}{ }_{(\mathrm{b})}\right]\right)
$$

where $D\left(\mathrm{~L}^{2} / \mathrm{s}\right)$ is the diffusion rate of $\mathrm{Ca}^{2+}$ in $\mathrm{Fe}(\mathrm{OH})_{3}$ as porous media [10], $\delta(\mathrm{L})$ is the thickness of the metal sediment, $\left[\mathrm{Ca}^{2+}{ }_{(\mathrm{s})}\right]$ is the concentration of $\mathrm{Ca}^{2+}$ at the surface of the limestone, and $\left[\mathrm{Ca}^{2+}{ }_{(\mathrm{b})}\right]$ is the concentration of $\mathrm{Ca}^{2+}$ in the bulk solution. For dissolution from a surface of area $A\left(\mathrm{~m}^{2}\right)$ into a fluid of volume $V\left(\mathrm{~m}^{3}\right)$, the mass balance necessitates that the rate of change of the concentration in the bulk solution is

$$
\frac{d\left[\mathrm{Ca}^{2+}\right]}{d t}=\frac{A}{V} J_{\mathrm{d}}
$$

The change in time referenced in the differential equation is representative of the time a specific volume of water has spent in the channel. This time scale is discussed in Section 4 when considering the figures produced by the model. Then combining this differential equation with the rate law, we 
EFFECTIVE RANGES OF A MODELED OPEN LIMESTONE CHANNEL

obtain

$$
\begin{aligned}
& \frac{D}{\delta}\left(\left[\mathrm{Ca}^{2+}{ }_{(\mathrm{s})}\right]-\left[\mathrm{Ca}^{2+}{ }_{(\mathrm{b})}\right]\right) \\
& \quad=\frac{1}{10}\left[k_{1}\left[\mathrm{H}^{+}{ }_{(\mathrm{s})}\right]+k_{2}\left[\mathrm{H}_{2} \mathrm{CO}_{3}{ }^{*}\right]+k_{3}\left[\mathrm{H}_{2} \mathrm{O}\right]-k_{4}\left[\mathrm{Ca}^{2+}{ }_{(\mathrm{s})}\right]\left[\mathrm{HCO}_{3}-(\mathrm{s})\right]\right] .
\end{aligned}
$$

This is overall a nonlinear equation dependent on the concentrations of calcium ions on the surface of the limestone, as well as in the water. The concentration of calcium at the surface is obtained by solving the differential equation (3.7). This new calcium concentration is then used to recalculate the equilbrium contrations of the other species using the process described in Section 2.

Because of the low solubility of $\mathrm{Fe}^{3+}$, it tends to precipitate when the $\mathrm{pH}$ value raises to some certain threshold. To calculate the iron precipitation, we consider the following reaction and its corresponding equilibrium equation $[7]$

$$
\begin{aligned}
& \mathrm{Fe}(\mathrm{OH})_{3}+3 \mathrm{H}^{+} \rightleftharpoons \mathrm{Fe}^{3+}+3 \mathrm{H}_{2} \mathrm{O} \\
& \log \left[\mathrm{Fe}^{3+}\right]=3.2-3 \mathrm{pH}
\end{aligned}
$$

The effect is added to the numerical solver to reflect the diffusion of calcium ions through the precipitation layer on the surface of limestone. The rate of dissolution is used to calculate the concentration of species in the next step.

\section{NumericAl RESUlts}

Both samples and numeric data were collected by engineering students at Saint Francis University under the "Limestone Channel at Swank 13 Mine" project. The Swank 13 mine is an abandoned underground coal 
EFFECTIVE RANGES OF A MODELED OPEN LIMESTONE CHANNEL

mine in Reade Township, northern Cambria County, Pennsylvania. An acid flow emerges out of the abandoned mine and is directed down a 1000 foot channel lined with limestone boulders approximately one foot thick, in order to neutralize the acidity of the water and precipitate iron and aluminum. Data was collected from the field and numerical computation was conducted in Matlab to fit the real data. Optimization toolbox was used to solve the nonlinear equation (3.8). A program based on Euler's Method is used to numerically compute the change of concentration of calcium ions along the channel as determined by the nonlinear rate equation. The parameters used by a differential equation solver built into the Matlab program are not compatible with the model for the OLC. Euler's Method allows for close observation of the change of parameters and hence to make subsequent adjustments. There are potential problems with each method of numerical computation. The ode45 differential equation solver built into Matlab was used first. This gave expected trends in the data, showing a gradual decline in $\mathrm{pH}$ and species change as the water progressed through the channel. However, when experimental data was inputed into the model, the ode45 was unable to produce an accurate result at any point in the channel. Euler's Method was used as a basic numeric solver to calculate final conditions using an easily understood method. The Euler's program was able to match the end conditions of the channel, but due to the linear nature, unable to obtain the curvature required to predict values in the center of the channel with accuracy. Other numeric methods may be able to predict conditions other than the end condition of the channel and should be studied further. For this paper, the information provided by the Euler's model will be used to make predictions based on the end conditions of the channel only. 
EFFECTIVE RANGES OF A MODELED OPEN LIMESTONE CHANNEL

Several tables and figures are shown as examples of data collected and model outputs. Table 1 shows data collected pertaining to depth and velocity measurements used as parameters in the model. Table 2 compares the values of concentration of calcium and $\mathrm{pH}$ values predicted by the model to experimentally measured values.

TABle 1. Averaged Measurements Applied to Model

\begin{tabular}{|c|c|c|c|c|c|c|}
\hline & Weir 2 & Site 1 & Site 2 & Site 3 & Weir 1 & Average \\
\hline V $(\mathrm{m} / \mathrm{s})$ & 0.253 & 0.152 & 0.199 & 0.294 & 0.175 & 0.213 \\
\hline V Max $\left(\mathrm{m} / \mathrm{s}^{2}\right)$ & 0.523 & 0.479 & 0.491 & 0.562 & 0.431 & 0.497 \\
\hline Width $(\mathrm{m})$ & 1.400 & 1.450 & 1.060 & 1.100 & 1.283 & 1.239 \\
\hline A $\left(\mathrm{m}^{2}\right)$ & 0.079 & 0.141 & 0.103 & 0.095 & 0.165 & 0.117 \\
\hline D $(\mathrm{m})$ & 0.081 & 0.104 & 0.099 & 0.092 & 0.127 & 0.101 \\
\hline FR $\left(\mathrm{m} / \mathrm{s}^{3}\right)$ & 0.032 & 0.022 & 0.019 & 0.037 & 0.023 & 0.027 \\
\hline
\end{tabular}

TABle 2. Comparison of $\mathrm{pH}$ data and model values

\begin{tabular}{|c|c|c|c|c|}
\hline & Model pH & Measured $\mathrm{pH}$ & ${\text { Model }[\mathrm{Ca}]^{*}}$ & Measured [Ca] \\
\hline Top Weir & 3.48 & 3.48 & 14.75 & 14.75 \\
\hline Site 1 & 3.53 & 3.56 & 15.58 & 16.12 \\
\hline Site 2 & 3.60 & 3.69 & 16.38 & 17.11 \\
\hline Site 3 & 3.67 & 3.77 & 17.14 & 17.52 \\
\hline Bottom Weir & 3.72 & 3.73 & 17.60 & 17.17 \\
\hline \multicolumn{5}{|c}{ *Values report in part per million (ppm) } \\
\end{tabular}

The values presented in Table 2 as model data were obtained by following the processes outlined in Section 2 and Section 3. Values from Table 1 were first used to specify the surface area and velocity inputs required by the model. Here the surface area parameter is the area of limestone exposed to the bulk water. This area is estimated as an open rectangular prism of uniform height and width. The average depth, $D$, and width measurements shown in Table 1 were used the height and width measurements of the 


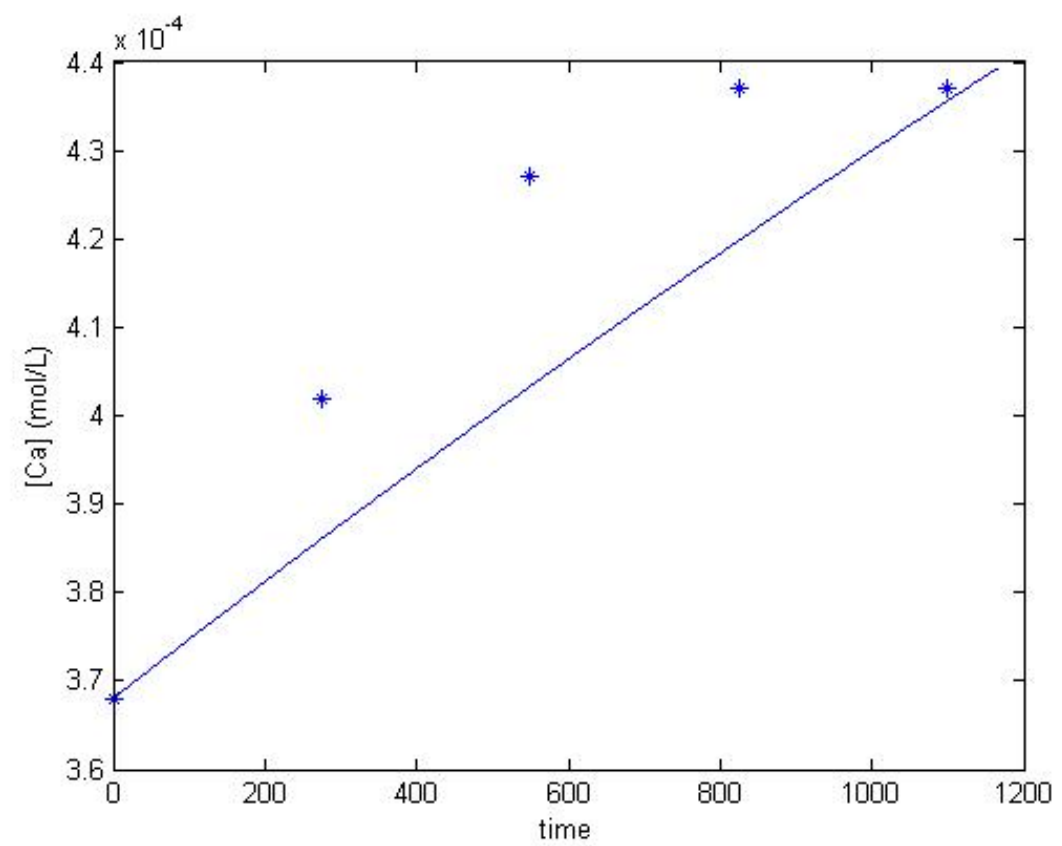

Figure 1. Comparison of Model and Experimental Calcium Data

channel to achieve the surface area estimate. The velocity, $V$, of the channel at all five measurement sites was averaged and this value used as the uniform velocity of the channel. The initial iron, calcium, and $\mathrm{pH}$ inputs were all as measured experimentally at the top of the channel. The flow rate of the channel, $F R$, is not used directly in the model but is contained in Table 1 so all data collected with the velocity measurements can be compared.

The calcium measurement from the top of the channel is used as an input to the speciation step detailed in Section 2. The speciation step is a subprogram made in Matlab that uses arrays of the coeffcients of the equilbrium conditions to create conditions nessecary to perform Newton-Raphson. From this step, the equilbrium concentrations of $\left[\mathrm{H}^{+}\right],\left[\mathrm{Ca}^{2+}\right]$, and $\left[\mathrm{HCO}_{3}{ }^{-}\right]$are calculated for the time that the volume of water enters the channel. Following this step the program checks if the iron precipitate layer has passed a threshold value for thickness. This is done by finding the difference between 


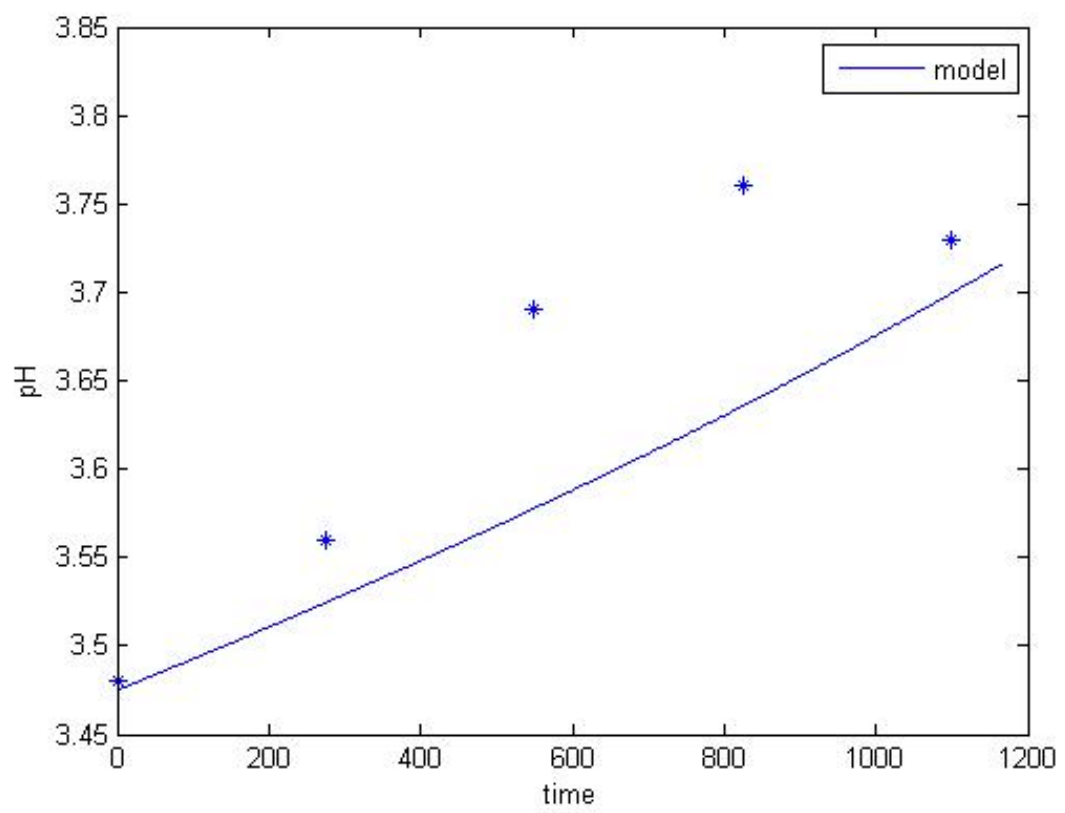

Figure 2. Comparison of Model and Experimental pH Data

the total amount of iron measured experimentally and the amount of iron predicted by the $\left[\mathrm{H}^{+}\right]$from the speciation step and equation (3.10). The difference between these values will be considered to be the amount of iron precipitated, from which a thickness of a precipitation layer is determined from the surface area available. If the thickness is under the threshold value the precipitate layer is insignificant, and the rate of dissolution can be found directly from equation (3.1). After the precipitate layer has overcome the threshold, a value of calcium in the bulk water must be obtained by solving the nonlinear differential equation (3.8). This value for calcium is used to recalculate the equilbrium concentrations using the speciation step. These corrected concentrations can then be applied to equation (3.1) to find the rate. The rate of dissolution is then used to find the calcium concentration in the next time step, and the process is repeated. 
EFFECTIVE RANGES OF A MODELED OPEN LIMESTONE CHANNEL

Figure 1 shows the change in the calcium concentration over the length of the channel compared to measured values. The time indicated on the axis of this figure is indicative of the time that the volume of water studied has been in the channel. This is done on the assumption that water flows with a velocity equal to the average velocity of the channel at all times. The time in the channel as indicated on the axis is obtained from the total length of the channel and the average velocity. For example, a sample of water would be approximately half-way through the channel at 600 seconds on the axis. The same sample would be in the channel for 1200 seconds total before exiting. Figure 2 shows the comparison of the $\mathrm{pH}$ value predicted by the model compared to measured values. The measured values of $\mathrm{pH}$ are indicated at the spot where each was measured along the length of the channel. When the $\mathrm{pH}$ value achieves a threshold value, iron precipitates start to appear, at this point the rate of change of $\mathrm{pH}$ values should slowly start to decrease. This expected behavior is not shown in the $\mathrm{pH}$ values predicted by the model. A possible explanation is the numeric method used to obtain these values over the time period. Euler's Method is usually used to predict the conditions of systems of linear equations, and so any values from this method will increase in a linear manner. In this case, the end conditions of the channel are the only significantly useful values produced by the model other than the known initial condition.

Following the collection of data and verification that the model can accurately predict the end conditions of a OLC, ranges were established for the parameters of the model. An operational range was found for the following values: iron concentration, calcium concentration, $\mathrm{pH}$ value, water velocity, and the temperature of the water. Here only the ranges will be stated. The full charts containing the data collected from running the program for each 
EFFECTIVE RANGES OF A MODELED OPEN LIMESTONE CHANNEL

parameter can be found in supplemental material. Each parameter's range was established based on whether results are practically or logically viable.

The OLC should be operational at all temperatures according to the model. In other words, any temperature input into the program will allow a reasonable $\mathrm{pH}$ change. So the kinetics of the chemical reactions are not affected by the change in temperature to a great degree and no range need be established. The $\mathrm{pH}$ range of the OLC was cut off when the $\mathrm{pH}$ ended at 7 , or when the water was in neutral, livable state. The full range of initial $\mathrm{pH}$ values for a working, armored OLC was determined to be between 2.30 and 4.00. For a given input value, the model was run an the output of final $\mathrm{pH}$ and calcium concentration was recorded. The input was then increased by $0.01 \mathrm{ppm}$ if the parameter was a concentration or $0.01 \mathrm{~m} / \mathrm{s}$ in the case of water velocity and output values were recored. The step size was chosen based of the number of significant digits that could experimentally be measured using spectroscopy or in the field with a $\mathrm{pH}$ meter and a flow tracker. When the difference between two consectutive outputs ceased to change with the input parameter, it was considered to be the extreme end of the range and the OLC would not treat water to a significant effect. Using this techinque, ranges were determined for intial calcium and iron concentrations, and average velocity of the water flow. An armored OLC of similar length should treat water with between 0.001 and $10.70 \mathrm{ppm}$ of initial iron centration. Similarily the range of initial calcium concentration ranges from 2.81 and $20.0 \mathrm{ppm}$. The effective average water velocity ranges between 0.05 and $2.60 \mathrm{~m} / \mathrm{s}$.

Now further explaination of what the ranges mean is needed. Not every value within these ranges will allow an OLC to treat acidic water back to ideal conditions. Only at extreme ends of the ranges is the $\mathrm{pH}$ of the water raised close to $\mathrm{pH}$ 7. Based on the model, an OLC will lose much of 
EFFECTIVE RANGES OF A MODELED OPEN LIMESTONE CHANNEL

its effectiveness once becoming armored. A stream available for treatment would naturally fall towards the optimal end of the range, so that when armoring begins the OLC is still effective to a degree. The ranges were also computed while varying only one input parameter at a time. A real stream would require an individual input for each parameter. Still these ranges would be useful in determining quickly whether a stream should be studied further to determine treatment.

\section{CONCLUSION AND FUTURE DISCUSSION}

In this project we have utilized a mathematical model of open limestone channel using Fick's first law and the rate law of calcite dissolution. The diffusion process is approximated by linear decrease, which is the steady state equation. The model can be shown to reflect experimental data taken from an existing OLC, but only the final conditions of the channel. The final conditions taken of the model were used to establish a range of values for $\mathrm{pH}$, iron and calcium concentration, and water velocity that would allow for effective treatment by an OLC.

However, both numerical and experimental data show that the effect of open limestone channel treatment is greatly reduced by the iron sediments, which is consistent with the conclusion made in [4].

There are several factors that need to be considered before proceeding further with this project. The $\mathrm{pH}$ increase predicted from the model is linear in nature while experiment data shows a curved fit. The reaction rates used to output the final $\mathrm{pH}$ could be altered to better reflect the actual system or a different numerical method could be used in the model. The ranges established would be most useful in study of an existing armored channel. Experimental data from a newly created OLC, could better reflect the effectiveness of an OLC on an unremediated stream. 
EFFECTIVE RANGES OF A MODELED OPEN LIMESTONE CHANNEL

\section{ACKNOWLEDGEMENT}

The authors would like to thank Dr. Joel Bandsra, Dr. Bill Strosnider, Dr. Edward Zovinka and their research students Sergio Carvajal, C. J. Spellmen, James Krug, Rebecca Krupa, and Caleb Weyant for the collection and analysis of the data collected from the Swank 13 site.

\section{FUNDING}

This work was supported by the National Science Foundation under Grant No. DUE-1161227.

\section{REFERENCES}

[1] F. H. PEARSON and A. J. MCDONNELL, Chemical kinetics of neutralization of acidic water by crushed limestone, in Proc. No. 18, Water Resources Problems Related to Mining, American Water Resources Association, Columbus, OH, 1974, pp. 85-98.

[2] F. H. PEARSON andA. J. MCDONNELL, Use of crushed limestone to neutralize acid waters, Journal of the Environmental Engineering Division, ASCE, Vol. 101, No. EE1, Proc. Paper 11131, 1975a, pp. 139-158.

[3] F. H. PEARSON and A. J. MCDONNELL, Limestone barriers to neutralize acidic streams, Journal of the Environmental Engineering Division, ASCE, Vol. 101, No. EE3, Proc. Paper 11382, 1975b, pp. 425-440.

[4] P. ZLEMKIEWICZ, J. SKOUSEN, and R. LOVETT, Open limestone channels for treating acid mine drainage: A new look at an old idea, Green Lands, 24(4)(1994), pp. 36-41.

[5] J. BANDSTRA, Y. LI, and N. WU, Mathematical modeling on open limestone channel, Mathematics Exchange, Vol. 9, 2014.

[6] C. A. CRAVOTTA and M. K. TRAHAN, Limestone drains to increase $\mathrm{pH}$ and remove dissolved metals from acidic mine drainage, Applied Geochemistry, 14(1999), pp. 581606.

[7] J. L. SCHNOOR and A. ZEHNDER, Environmental Modeling: Fate and Transport of Pollutants in Water, Air, and Soil, Environmental Science and Technology: A Wiley-Interscience Series of Texts and Monographs, 1996. 
EFFECTIVE RANGES OF A MODELED OPEN LIMESTONE CHANNEL

[8] H. S. HARNED and S. R. SCHOLES JR., The Ionization Constant of $\mathrm{HCO}_{3}{ }^{-}$- from 0 to $50^{\circ}$, Journal of American Chemical Society, 63(6)(1941), pp. 1706-1709.

[9] L. N. PLUMmeR, T. M. L. WIGLEY, and D. L. PARKHURST, The kinetics of calcite dissolution in $\mathrm{CO}_{2}$-water systems at 5 to $60^{\circ} \mathrm{C}$ and 0.0 to 1.0 atm $\mathrm{CO}_{2}$, American Journal of Science, 278(1978), pp. 179-216.

[10] B. E. LOGAN, Environmental Transport Processes, John Wiley \& Sons, Inc., New York, 2012. 